CAMARGO, Carolina; SPERANDIO, Marilin Soares. Mulher e a condição da sustentabilidade social: uma análise a partir de Amartya Sen. Revista Eletrônica Direito e Política, Programa de PósGraduação Stricto Sensu em Ciência Jurídica da UNIVALI, Itajaí, v.11, n.3, 30 quadrimestre de 2016. Disponível em: www.univali.br/direitoepolitica - ISSN 1980-7791

\title{
MULHER E A CONDIÇÃO DA SUSTENTABILIDADE SOCIAL: UMA ANALISE A PARTIR DE AMARTYA SEM
}

WOMEN AND THE CONDITION OF SOCIAL SUSTAINABILITY: AN ANALYSIS FROM AMARTYA SEN

Carolina Camargo ${ }^{1}$

Marilin Soares Sperandio ${ }^{2}$

SUMÁRIO: Introdução; 1. Violência: Medo e Obediência; 1.1. Breves considerações da evolução dos direitos das mulheres na sociedade; 2. Amartya Sen e a Condição de Agente da Mulher; 2.1. A Condição de agente ativo; Considerações finais; Referências das fontes citadas.

\section{RESUMO}

Este artigo tem como objetivo investigar a condição de agente da mulher em Sen, e neste contexto, traçar o liame entre o exercício das capacidades e condições, como instrumentos que possam propiciar a oportunidade de emancipação da mulher. Nesta senda, um dos fatores que contribui para uma não sustentabilidade social é a violência contra a mulher. A presente pesquisa tratará especificamente da vítima de violência doméstica, e neste viés, investigar se a sustentabilidade social da mulher depende da democracia, partindo da concepção Condição de Agente em Sen?

Palavras-Chave: Condição de Agente da Mulher; Violência doméstica; Democracia.

\section{ABSTRACT}

This article aims to investigate the condition of women's agent in Sen, and in this context, draw the link between the exercise of capacities and conditions, as

\footnotetext{
${ }^{1}$ Graduada em Direito. Advogada. Mestranda em Direito da Faculdade Meridional IMED/RS, Pesquisadora no Centro de Pesquisa do Programa de Pós-Graduação Stricto Sensu em Direito IMED/RS. E-mail: carolcamargo11@yahoo.com.br

${ }^{2}$ Mestranda em Direito (IMED). Membro do Kathársis - Centro de Estudos em Direito e Literatura e Membro Efetivo da Rede Brasileira Direito e Literatura - RDL. E-mail: mss.marilin@gmail.com
} 
CAMARGO, Carolina; SPERANDIO, Marilin Soares. Mulher e a condição da sustentabilidade social: uma análise a partir de Amartya Sen. Revista Eletrônica Direito e Política, Programa de PósGraduação Stricto Sensu em Ciência Jurídica da UNIVALI, Itajaí, v.11, n.3, 30 quadrimestre de 2016. Disponível em: www.univali.br/direitoepolitica - ISSN 1980-7791

instruments that can provide the opportunity for women's emancipation. In this path, one of the factors that contributes to a non-social sustainability is violence against women. The present research will deal specifically with the victim of domestic violence, and in this bias, investigate whether the social sustainability of women depends on democracy, starting from the concept of Agent's Condition in Sen?

Keywords: Condition of Woman Agent; Domestic violence; Democracy.

\section{INTRODUÇÃO}

O desenvolvimento dos indivíduos na sociedade democrática está intimamente ligado ao exercício das liberdades e capacidades. Para que isso ocorra, é imprescindível que o Estado remova fontes de privação de liberdade e permita a ampliação de oportunidades, capacidades, escolhas e o desenvolvimento da política dos Estados de forma justa e igualitária.

Um país sob um regime democrático propicia a seu povo a oportunidade de diálogo sobre problemas sociais que afligem suas comunidades, sendo assim, é na democracia que direitos e garantias passam a existir concretamente e são total ou parcialmente efetivadas, decorrentes da vontade soberana do povo.

Para que direitos e garantias possam ter efetividade é necessário que as condições e oportunidades cheguem a todos os cidadãos de forma igualitária. Nesta senda, as desigualdades sociais são fortemente combatidas e evitadas em países democráticos, assim, a garantia de direitos fundamentais como, por exemplo, educação e trabalho é prioridade do Estado através de Políticas Públicas.

Uma parcela das carências enfrentadas pelas populações de baixa renda são reflexos da ineficácia ou inexistência destas políticas públicas. Quanto menor o grau de instrução do individuo maior é a dependência deste cidadão ao Estado. Ademais, o custo das Politicas públicas restringe a sua oferta a todos os cidadãos 
CAMARGO, Carolina; SPERANDIO, Marilin Soares. Mulher e a condição da sustentabilidade social: uma análise a partir de Amartya Sen. Revista Eletrônica Direito e Política, Programa de PósGraduação Stricto Sensu em Ciência Jurídica da UNIVALI, Itajaí, v.11, n.3, 30 quadrimestre de 2016. Disponível em: www.univali.br/direitoepolitica - ISSN 1980-7791

de maneira igualitária, visto que, limita sua utilização a quem realmente dela necessita.

Infelizmente na prática a distribuição de renda e a oferta de serviços básicos como, por exemplo, saúde, saneamento e educação são destinados a grandes centros, negligenciando a população mais carente do país que não tem condições de exercer a condição de agente na sociedade.

A mulher que é vítima historicamente da desigualdade social sofre com a restrição de direitos e garantias provenientes do Estado, nesta senda, quando se torna vítima de violência doméstica, resta refém de seu companheiro que por ser homem possui mais oportunidades de trabalho e estudo, fortalecendo a condição de dependência absoluta da vítima com o agressor.

Portanto, a responsabilidade do Estado pela defesa e efetividade de direitos é fundamental para a quebra do paradigma da violência doméstica. Diante disto, é imprescindível o conjunto das capacidades, que através de instrumentos como, por exemplo, trabalho, renda, saúde, educação, direito a propriedade, integração social, e decisão politica possam ser individualmente escolhidas e exercidas pela condição de agente em Sen.

No que tange ao debate sobre a relevância do tema da violência contra a mulher, é necessário contextualizar que a imposição por meio da força física, advém dos primórdios, e com a evolução da sociedade na história, não foi possível erradicar esta conduta por vários fatores.

Dentre estes fatores, dois merecem destaque. O primeiro referente à imposição da força bruta como legitimação do poder e assim neste critério, por ser mais fraca que o homem biologicamente a mulher permanece excluída da sociedade que necessita dos mais fortes e o segundo, o fortalecimento seletivo Estatal pela 
CAMARGO, Carolina; SPERANDIO, Marilin Soares. Mulher e a condição da sustentabilidade social: uma análise a partir de Amartya Sen. Revista Eletrônica Direito e Política, Programa de PósGraduação Stricto Sensu em Ciência Jurídica da UNIVALI, Itajaí, v.11, n.3, 30 quadrimestre de 2016. Disponível em: www.univali.br/direitoepolitica - ISSN 1980-7791

não observância das minorias como negros, mulheres e deficientes físicos privilegiando apenas os homens, ricos e poderosos.

Outro fator que denota preocupação especial é como a cultura, os costumes e a religião influenciam neste processo de dependência da mulher ao agressor. Por certa feita, há culturas e religiões que trazem em seus modos de vida e escrituras sagradas, condutas que condicionam a mulher a servir e ser obediente ao homem mesmo sendo vitima de violência.

No que se refere à violência doméstica, há culturas que legitimam a mulher como objeto e então o marido/agressor tem o "direito" de puni-la quando não atende suas exigências, no Brasil no ano de 2006 foi sancionada a Lei Maria da Penha 11.340, que visa proteger a mulher vitima de violência doméstica e punir o agressor.

Há menos de um ano os altos índices de homicídio motivado por violência doméstica ou gênero, resultaram na inserção da qualificadora no artigo 121 do Código Penal brasileiro em decorrência da Lei do Feminicídio no 13.104/2015, demonstrando a s e a preocupação do Estado em impor uma sanção especifica e estes casos visando a redução da incidência por meio da punição do agressor.

Sendo assim, a violência doméstica e a dependência da vítima ao agressor são atribuídas a fatores distintos de acordo com a realidade da sociedade que a vítima está inserida. Ademais, a condição de agente da mulher em Sen, está fortemente condicionada a democracia e capacidades instrumentais oportunizadas pelo ente estatal.

A Condição de Agente ativa das mulheres na filosofia de Amartya Sen demonstra a realidade enfrentada na sociedade atual, que busca a igualdade entre homens e mulheres e a dignidade. A mulher quando agente ativa passa a ser a 
CAMARGO, Carolina; SPERANDIO, Marilin Soares. Mulher e a condição da sustentabilidade social: uma análise a partir de Amartya Sen. Revista Eletrônica Direito e Política, Programa de PósGraduação Stricto Sensu em Ciência Jurídica da UNIVALI, Itajaí, v.11, n.3, 30 quadrimestre de 2016. Disponível em: www.univali.br/direitoepolitica - ISSN 1980-7791

gerenciadora da sua vida e de seu seio familiar, sendo assim é a oportunidade de empoderamento que transforma e da força para que consiga desempenhar um papel na sustentabilidade social da mulher.

\section{VIOLÊNCIA: MEDO E OBEDIÊNCIA}

A violência, salvo melhor juízo, sempre esteve presente na vida do homem, como por exemplo, na era primitiva onde a utilizava para sobreviver através da caça, para disputar um território ou para conquistar uma fêmea. Também foi a ferramenta usada para demonstrações de poder por ditadores, reis, inquisidores, presidentes e tantos outros que com o passar dos séculos na história foram moldando a sociedade atual.

Sendo assim, a violência é a ferramenta utilizada para auferir o poder, pois quanto mais se impõem medo e opressão a um povo, maior será o reconhecimento da força do soberano e a resposta do povo será a obediência pelo medo da sanção.

A aplicação de uma pena ao individuo que inflige a lei do soberano, representa o exercício da vontade unilateral do poderoso que, quando contrariado aplica uma vingança (privada) como, por exemplo, mutilações, pena de morte, pena perpétua, enforcamento, pena capital dentre tantas outras cruéis em comparação a restritiva de liberdade que é mais branda.

Segundo John Rawls, [...] "só se cogita justiça onde há igualdade, fora daí o forte faz o que quer, e o fraco aceita o que tem de aceitar ${ }^{\prime 3}$. Essa afirmativa ilustra o grande problema da justiça e o poder, não se pode considerar justiça

\footnotetext{
3 John Rawls. Direito dos Povos. Tradução de Luis Carlos Borges. São Paulo: Martins Fontes, 2001. P. VII
} 
CAMARGO, Carolina; SPERANDIO, Marilin Soares. Mulher e a condição da sustentabilidade social: uma análise a partir de Amartya Sen. Revista Eletrônica Direito e Política, Programa de PósGraduação Stricto Sensu em Ciência Jurídica da UNIVALI, Itajaí, v.11, n.3, 30 quadrimestre de 2016. Disponível em: www.univali.br/direitoepolitica - ISSN 1980-7791

em meio a desigualdade social de um povo, pois para tanto, os indivíduos deveriam se encontrar em igualdade. Sendo assim, podemos afirmar que não há justiça quando as condições e oportunidades não são para todos, logo, sem poder escolher por não haver opções o forte sobrepõe o fraco.

No que tange a evolução histórica, a violência que inicialmente era absoluta (vingança ilimitada), avança com o desenvolvimento da sociedade e passa por etapas intermediarias como, por exemplo, a vingança limitada (Lei de Talião) até os momentos atuais de controle Estatal (Estado como terceiro árbitro) que tipifica condutas a partir do senso comum.

Neste viés da evolução, a violência passa a ser fragilizada em seu contexto de superioridade, posto que se enfraquece enquanto se enaltecem outros pontos de controle estatal que valorizam e fazem crescer os indivíduos na sociedade. A mulher recepciona estas melhorias decorrentes das alterações da sociedade, uma vez que, desenvolve autonomia através de instrumentos como, por exemplo, trabalho (renda) e educação afastando-se da vulnerabilidade social em razão da imposição da violência.

Portanto, na sociedade contemporânea, há outras formas de conquistar o poder, e com o passar dos séculos, a força deixou de ser o único instrumento viável de legitimação. Podemos afirmar que nos dias atuais, as mulheres ocupam posições que antes somente eram de homens pelo mérito intelectual e não mais pela imposição da força física que gerava uma identidade superior do homem.

No contexto familiar, fatores que supostamente legitimam a violência ao longo do tempo como força e poder, podem estar atrelados a maneira como os indivíduos se relacionavam nos períodos que antecederam a sociedade contemporânea, eliminando os mais fracos, que não detinham condições de cooperar com os demais integrantes da tribo, clã, família, vila, comunidade etc. 
CAMARGO, Carolina; SPERANDIO, Marilin Soares. Mulher e a condição da sustentabilidade social: uma análise a partir de Amartya Sen. Revista Eletrônica Direito e Política, Programa de PósGraduação Stricto Sensu em Ciência Jurídica da UNIVALI, Itajaí, v.11, n.3, 30 quadrimestre de 2016. Disponível em: www.univali.br/direitoepolitica - ISSN 1980-7791

A cultura, religião e hábitos arraigados na sociedade podem ser atribuídos como um dos vetores responsáveis pela afirmação da negação da condição de agente da mulher na sociedade, pois historicamente destacam o homem como chefe da família e a mulher como sua propriedade e dependente.

Assim, a dificuldade de afirmação da mulher na sociedade, demonstra a fragilidade do empoderamento diante da realidade de uma sociedade governada e comandada por um lapso temporal extenso somente por homens.

Contudo, cumpre destacar, que a evolução da sociedade promoveu inovações na constituição das famílias, divisão das tarefas, bem como na aquisição e divisão dos bens, resultando numa mitigação da imposição do homem "chefe" de família.

Esta "impressão" da perda ou diminuição do poder é um dos fatores que desencadeiam a violência contra a mulher que perpassa gerações e nações e independe da condição econômica dos países, sendo assim, segundo Sen são problemas velhos que convivem com os novos e limitam a condição de agente da mulher mesmo na era da sociedade globalizada. Leciona Sem:

[...] as diferentes regiões do globo estão agora mais estreitamente ligadas do que jamais estiveram, não só no campo da troca, do comércio e das comunicações, mas também quanto a ideias e ideais interativos. Entretanto, vivemos igualmente em um mundo de privação, destituição e opressão extraordinárias. Existem problemas novos convivendo com antigos - a persistência da pobreza e de necessidades essenciais não satisfeitas, fomes coletivas de fome crônica muito disseminadas, violência de liberdades politicas elementares e de liberdades formais básicas, ampla negligência diante dos interesses da condição de agente das mulheres e ameaças cada vez mais graves ao nosso meio ambiente e à sustentabilidade de nossa vida econômica e social. Muitas dessas privações podem ser encontradas, sob uma ou outra forma, tanto em países ricos como em países pobres $^{4}$.

\footnotetext{
${ }^{4}$ SEN, Amartya. Desenvolvimento como liberdade, 2010, p.9.
} 
CAMARGO, Carolina; SPERANDIO, Marilin Soares. Mulher e a condição da sustentabilidade social: uma análise a partir de Amartya Sen. Revista Eletrônica Direito e Política, Programa de PósGraduação Stricto Sensu em Ciência Jurídica da UNIVALI, Itajaí, v.11, n.3, 30 quadrimestre de 2016. Disponível em: www.univali.br/direitoepolitica - ISSN 1980-7791

Nesta senda, a conduta violenta se estabelece em diversos segmentos, podendo ser ou estar ligada a muitas causas e ambientes diversos. A presente pesquisa visa investigar especificamente a violência doméstica e os critérios da condição de agente e das capacidades de Sen, uma vez que a violência doméstica que ocorre no âmbito familiar tem como característica a violação de direitos fundamentais e sociais que ocorrem de maneira silenciosa.

A violência doméstica se materializa geralmente dentro de casa e longe do contato com o mundo exterior, submetendo a vítima a vários tipos de violência como a moral, física e psicológica. Assim, fatores como a dificuldade de percepção de terceiros da violência, e da inércia de denúncia partindo da própria vítima, dificultam que esta infringência normativa seja punida ou evitada e em muitos casos somente é descoberto quando resulta em tentativa ou homicídio consumado.

Ademais, a violência contra a mulher é corriqueira e apresenta resultados alarmantes em várias regiões do Brasil, conforme analisado nas estatísticas do Mapa da Violência de 2015 as formas do emprego da violência física são: lesões leves, emprego de força bruta (espancamento), disparos de arma de fogo e lesões por instrumentos perfurocortante, estes tipos de lesões em alguns casos consumam homicídios e revelam a crueldade que as vitimas são submetidas.

A origem da violência contra a mulher encontra-se interligada a várias causas como já anteriormente exposto como, por exemplo, a cultura patriarcal, religião, costumes e a vulnerabilidade social pela inércia do Estado, para a promoção de políticas públicas de proteção a mulher.

No Brasil na ultima década, ocorreram avanços como a Lei Maria da Penha que visa dar suporte e proteção às vítimas através de medidas de segurança como, 
CAMARGO, Carolina; SPERANDIO, Marilin Soares. Mulher e a condição da sustentabilidade social: uma análise a partir de Amartya Sen. Revista Eletrônica Direito e Política, Programa de PósGraduação Stricto Sensu em Ciência Jurídica da UNIVALI, Itajaí, v.11, n.3, 30 quadrimestre de 2016. Disponível em: www.univali.br/direitoepolitica - ISSN 1980-7791

por exemplo, afastamento do agressor lar e casas de acolhimento para as vítimas e seus filhos.

Partindo da análise da teoria de Amartya Sen, pressuposto para a presente pesquisa, as vítimas de violência doméstica pertencem a categoria da condição de não agente visto que, encontram-se limitadas a dependência do agressor, sendo assim, não consegue sair do circulo da violência pois faltam elementos que propiciem a sua inserção na condição de agente ativa através da emancipação.

Para que ocorra então a reversão desta condição, é imprescindível que haja instrumentos disponíveis para um amplo exercício da condição de agente ativa da mulher como, por exemplo, trabalho, renda, direito a propriedade, saúde com qualidade, saneamento básico, educação e o desenvolvimento das capacidades proporcionadas pelo Estado.

Com efeito, a democracia é indispensável para o desenvolvimento econômico e social de um país, pois através da independência concedida pela tripartição dos poderes, formado pelo judiciário, executivo e legislativo baseado na teoria de Montesquieu, retira o poder absoluto do governante, delegando a fiscalização, legislação e punição a demais órgãos. Assim sendo, o Estado tem o dever de promover a seus cidadãos o combate as desigualdades sociais e a sua proteção nas relações díspares.

É útil, neste contexto, examinar a origem da democracia que para Martha Nussbaum decorre da tradição de um contrato social, pactuado por pessoas que se unem para o desenvolvimento de interesses de comum acordo, e regidos por leis:

La tradición occidental ha producido muchas teorias de la justicia social. Una de las mas poderosas y duraderas ha sido la idea del contrato social, según la cual un conjunto de individuos racionales se unen en busca de un beneficia 
CAMARGO, Carolina; SPERANDIO, Marilin Soares. Mulher e a condição da sustentabilidade social: uma análise a partir de Amartya Sen. Revista Eletrônica Direito e Política, Programa de PósGraduação Stricto Sensu em Ciência Jurídica da UNIVALI, Itajaí, v.11, n.3, 30 quadrimestre de 2016. Disponível em: www.univali.br/direitoepolitica - ISSN 1980-7791

mutuo, y acuerdan abandonar el estado de naturaliza para gobernarse a si mismos a traves de la ley ${ }^{5}$.

Partindo-se desta concepção tradicional, pode-se afirmar que a democracia é um contrato social no qual foi redigido e pactuado por um grupo seleto de homens considerados produtivos. Por sua vez, a mulher por não ser considerada produtiva assim como as demais minorias, não pode para participar do processo de democratização.

Segundo Nussbaum:

A pesar de las grandes contribuciones que ha realizado esta tradición y del valor que conserva actualmente, sus ejemplos modernos se revelan insuficientes para responder a tres de los problemas de justicia más acuciantes del mundo actual. Los teóricos clásicos asumieron en todos los casos que los agentes contratantes eran hombres más o menos iguales en capacidad y aptos para desarrollar una actividad económica productiva. Por esta razón excluyeron de la posición negociadora a las mujeres (consideradas no «productivas»), a los niños y a las personas mayores, aunque sus intereses podían quedar representados par las partes presentes. Las doctrinas contemporáneas del han ractificado en cierta medida estas omisiones, que ya resultan llamativas en los siglos XVII y XVM, aunque la idea de que la familia es una esfera privada imune a la ley y al contrato no ha recibido siempre la crítica frontal que merece ${ }^{6}$.

Portanto a democracia em sua essência não foi destinada a proteger minorias como as mulheres, e sim somente os interesses em comum dos homens "produtivos" organizados entre si. É inegável que a evolução da democracia e a ampliação do debate introduziram as mulheres como sujeitos de direitos, mas, para que estes direitos sejam reconhecidos, é indispensável que o Estado oferte instrumentos eficazes.

\footnotetext{
${ }^{5}$ NUSSBAUM, Martha C. The Frontiers of justice: disability, nationality, species membership.
} Cambridge: Harvard University Press, 2005. P.23

${ }^{6}$ NUSSBAUM, Martha C. The Frontiers of justice: disability, nationality, species membership. Cambridge: Harvard University Press, 2005. P.35 
CAMARGO, Carolina; SPERANDIO, Marilin Soares. Mulher e a condição da sustentabilidade social: uma análise a partir de Amartya Sen. Revista Eletrônica Direito e Política, Programa de PósGraduação Stricto Sensu em Ciência Jurídica da UNIVALI, Itajaí, v.11, n.3, 30 quadrimestre de 2016. Disponível em: www.univali.br/direitoepolitica - ISSN 1980-7791

Sen aduz que, há uma restrição individual do que dispomos em razão da disponibilidade Estatal, "[...] a condição de agente de cada um é inescapavelmente restrita e limitada pelas oportunidades sociais e econômicas que dispomos ${ }^{\prime 7}$, assim, a ascensão da condição de agente requer instrumentos acessíveis aos indivíduos que proporcionam o exercício da condição de agente.

Não se pode olvidar, que os índices da violência de gênero com o passar dos anos tem aumentado bruscamente, e a sensação de impotência dos órgãos responsáveis como o governo, judiciário e demais instituições refletem a dificuldade de garantir segurança às mulheres devido a violência doméstica ocorrer dentro das casas e de forma silenciosa.

A violência contra a mulher sempre existiu, não é um fenômeno do século atual e tampouco pode ser atribuído ao século passado, não se sabe exatamente quando se iniciou, mas para a presente pesquisa partiremos da análise da obra o Martelo das Feiticeiras do ano de 1487 que deu legitimação a práticas absurdas ocorridas no período da inquisição de 1450 - 1750 contra as mulheres.

Como é possível perceber, mesmo com significativas mudanças ocorridas na sociedade, a violência permanece arraigada, tornando-se parte do cotidiano das pessoas. Sendo assim, a discussão no meio acadêmico e cientifico é de suma importância, para a investigação das causas e possíveis soluções, para a redução das taxas da violência doméstica no Brasil que segundo o mapa da violência de 2015 crescem há anos.

Assim, por se tratar de um tema atrelado a democracia e direitos fundamentais a análise da Lei no 11.340 de 2006, que já completou dez anos e demais dispositivos atinentes a proteção que visem assegurar o resgate e desenvolvimento da vitima de violência doméstica na concepção de Amartya Sen apresenta relevância jurídica, social e política.

\footnotetext{
7 SEN, Amartya. Desenvolvimento como liberdade. 2010, p.10
} 
CAMARGO, Carolina; SPERANDIO, Marilin Soares. Mulher e a condição da sustentabilidade social: uma análise a partir de Amartya Sen. Revista Eletrônica Direito e Política, Programa de PósGraduação Stricto Sensu em Ciência Jurídica da UNIVALI, Itajaí, v.11, n.3, 30 quadrimestre de 2016. Disponível em: www.univali.br/direitoepolitica - ISSN 1980-7791

\subsection{BREVES CONSIDERAÇÕES DA EVOLUÇÃO DOS DIREITOS DAS MULHERES NA SOCIEDADE}

A mulher para o direito romano não possuía capacidade, logo, não tinha direitos e era considerada como um objeto, quando menina era propriedade do pai, posteriormente do marido e em caso de viuvez passava a integrar como objeto da propriedade da família do marido.

A evolução da condição jurídica da mulher no Brasil ocorreu de forma lenta, e teve como marcos iniciais legislações como o Estatuto da Mulher Casada, a Consolidação das leis de trabalho, a Consolidação das Leis da Previdência Social e algumas aparições nas constituições anteriores.

Assim, por muitos anos a mulher teve uma educação diferenciada da educação destinada ao homem, pois era educada exclusivamente para servir ao homem, cuidar dos filhos e das tarefas da casa. Na época do Brasil-Colônia quando a Igreja deu inicio a educação não incluía as mulheres visto que a sociedade era patriarcal, cultuando o homem como núcleo essencial da família.

Logo, a violência doméstica era permitida porque a mulher era considerada propriedade do marido, podendo ele aplicar castigos e punições pela desobediência da sua vontade. No ano de 1890 com o Decreto Lei no 181, a liberdade de punir e castigar a mulher e os filhos foi retirada do direito do marido, que manteve o domínio patriarcal porem vedando a violência contra a mulher e os filhos.

É possível perceber esta coisificação da mulher submissa no Código Civil de 1916 que reafirmou os princípios conservadores e patriarcais, e vinculou a limitação dos atos da vida civil da mulher a anuência do marido como, por exemplo, o artigo 242 que aduz:

I. Artigo 242 do Código Civil de 1916: A mulher não pode sem o consentimento do marido:

II. Praticar atos que este não poderia sem o consentimento da mulher; 
CAMARGO, Carolina; SPERANDIO, Marilin Soares. Mulher e a condição da sustentabilidade social: uma análise a partir de Amartya Sen. Revista Eletrônica Direito e Política, Programa de PósGraduação Stricto Sensu em Ciência Jurídica da UNIVALI, Itajaí, v.11, n.3, 30 quadrimestre de 2016. Disponível em: www.univali.br/direitoepolitica - ISSN 1980-7791

III. Alienar, ou gravar de ônus real, os imóveis de seu domínio, qualquer que seja o regime dos bens;

IV. Alienar os seus direitos reais sobre imóveis de outrem;

V. Aceitar ou repudiar herança ou legado;

VI. Aceitar tutela, curatela ou outro múnus públicos;

VII. Litigar em juízo civil ou comercial, a não ser nos casos indicados nos arts. 248 e 251;

VIII. Exercer profissão;

IX. Contrair obrigações, que possam importar em alheação dos bens do casal;

\section{Aceitar mandato.}

A relação de poder do homem sobre a mulher vem arraigada desde a era primitiva, passando pelas demais épocas até chegar no modelo de família contemporânea nos dias atuais, sendo assim, resquícios da submissão da mulher ainda é muito presente nos relacionamentos afetivos condicionando-as muitas vezes a um circulo vicioso de inferioridade e violência decorrentes da condição de não agente.

A violência contra a mulher ocorre em diversos espaços e modos, não há como definir uma classe social em que a violência prepondere, logo, os fatores que desencadeiam práticas violentas estão ligados a várias causas, podendo ser referidas algumas como gênero, religião, cultura, e a discriminação que ocorre na vítima para com ela mesma.

O empoderamento da mulher é atualmente, a bandeira dos grupos de defesa dos direitos das mulheres, que lutam por igualdade gênero, direitos e principalmente pela proteção contra abusos e violência sofridos por meninas e mulheres. A adequação da legislação, para auxiliar as vítimas desta infringência é de suma importância, uma vez que, a judicialização das demandas cresce pelo reconhecimento do crime e a consequente denúncia.

Sendo assim, o Estado é também responsável por garantir que os instrumentos necessários para o desenvolvimento da mulher na sociedade possa estar 
CAMARGO, Carolina; SPERANDIO, Marilin Soares. Mulher e a condição da sustentabilidade social: uma análise a partir de Amartya Sen. Revista Eletrônica Direito e Política, Programa de PósGraduação Stricto Sensu em Ciência Jurídica da UNIVALI, Itajaí, v.11, n.3, 30 quadrimestre de 2016. Disponível em: www.univali.br/direitoepolitica - ISSN 1980-7791

disponível de forma igualitária, uma vez que segundo a Constituição Federal de 1988 em seu artigo 50, I, a mulher e o homem são iguais em direitos e obrigações $^{8}$, devendo pela vulnerabilidade da mulher o ente estatal promover Politicas Públicas que visem dar garantia e efetividade a segurança das mulheres que historicamente são vítimas de violência.

Amartya Sen parte de um contexto onde o regime do Estado para propiciar estes instrumentos deverá estar abarcado por uma democracia, pois somente assim, o povo titular do poder soberano poderá fiscalizar e exigir que as necessidades econômicas daquela comunidade possam efetivamente ser satisfeitas, demonstrando a importância dos direitos políticos e civis básicos para o desenvolvimento.

Sobre o poder e dinamismo da democracia, afirma Sen:

1) sua importância direta para a vida humana associada a capacidades básicas (como a capacidade de participação política e social); 2)seu papel instrumental de aumentar o grau em que as pessoas são ouvidas quando expressam e defendem suas reivindicações de atenção política (como as reivindicações ne necessidades econômicas);3) seu papel construtivo na conceituação de "necessidades" (como a compreensão das "necessidades econômicas" em um contexto social ${ }^{9}$.

O trabalho, o voto, a independência financeira, o reconhecimento como sujeito de direitos, a escolaridade e o direito a propriedade foram conquistas significativas das mulheres na sociedade atual. No Brasil, mesmo depois da conquista destes direitos e da exclusão da família com viés exclusivamente patriarcal, a mulher ainda sofre com discriminações de gênero e imposição da vontade do homem pela violência.

Posto Isto, cabe salientar que a violência contra a mulher cresce assustadoramente, como se pode perceber pelas estatísticas do Mapa da

\footnotetext{
8 Artigo 50, I da Constituição Federal de 1988: Homens e mulheres são iguais em direitos e obrigações, nos termos desta Constituição

9 SEN, Amartya. Desenvolvimento como liberdade. 2010,p.195
} 
CAMARGO, Carolina; SPERANDIO, Marilin Soares. Mulher e a condição da sustentabilidade social: uma análise a partir de Amartya Sen. Revista Eletrônica Direito e Política, Programa de PósGraduação Stricto Sensu em Ciência Jurídica da UNIVALI, Itajaí, v.11, n.3, 30 quadrimestre de 2016. Disponível em: www.univali.br/direitoepolitica - ISSN 1980-7791

Violência de 2015 que trazem dados contundentes para comprovar o alarmante crescimento de índices de homicídios contra a mulher no Brasil:

Pelos registros do SIM, entre 1980 e 2013, num ritmo crescente ao longo do tempo, tanto em número quanto em taxas, morreu um total de 106.093 mulheres, vitimas de homicídio. Efetivamente o número de vítimas passou de 1.353 mulheres em 1980, para 4.762 em 2013, um aumento de $252 \%$. A taxa, que em 1980 era de 2,3 vítimas por 100 mil, passa para 4,8 em 2013, um aumento de $111 \%{ }^{10}$.

Segundo o mesmo relatório, o Brasil possui 5.565 municípios e Tramandaí no Rio Grande do Sul integra o rol das 100 cidades com maior índice de homicídios contra mulheres, ocupando a 50a posição com uma população de 21.906 habitantes dos quais mais de dez mil são mulheres e a taxa de homicídios chega a 12,8 por 100 mil habitantes.

De fato, a violência se encontra em evidencia, e os dados revelam a ineficácia de mecanismos legais como leis e políticas públicas para a repressão do crime de homicídio praticado contra mulheres.

Um dos fatores para o fortalecimento e reincidência deste crime pode ser atribuído à carência de denúncia partindo da vítima, uma vez que a ação penal desta infringência normativa é incondicionada a representação, de titularidade do Ministério Público, mas que, depende da comunicação as autoridades competentes para a averiguação dos fatos e aplicação de medidas de proteção cabíveis ao caso concreto.

Nos dias atuais, surge a necessidade da criação de ferramentas de proteção e debates frequentes, que objetivam frear a expansão da violência. A mudança social motivada pela construção do bem-estar das mulheres é indispensável, para emancipação das vítimas que necessitam com urgência erradicar as desigualdades sociais através da Condição de Agente. Referente à importância da preocupação com o bem-estar Sen:

\footnotetext{
10 Mapa da Violência 2015. Homicídio de mulheres no Brasil, p.11: Disponível em www.mapadaviolencia.org.br
} 
CAMARGO, Carolina; SPERANDIO, Marilin Soares. Mulher e a condição da sustentabilidade social: uma análise a partir de Amartya Sen. Revista Eletrônica Direito e Política, Programa de PósGraduação Stricto Sensu em Ciência Jurídica da UNIVALI, Itajaí, v.11, n.3, 30 quadrimestre de 2016. Disponível em: www.univali.br/direitoepolitica - ISSN 1980-7791

A condição de Agente ativa das mulheres não pode, de nenhum modo sério, desconsiderar a urgência de retificar muitas dificuldades que arruínam o bem-estar das mulheres e as sujeitam a um tratamento desigual; assim, o papel da condição de agente tem de concentrar-se, em grande medida, também no bem-estar feminino. Analogamente, vindo pelo lado oposto, qualquer tentativa prática de aumentar o bem-estar feminino não pode deixar de recorrer a condição de agente das próprias mulheres para ocasionar tal mudança ${ }^{11}$.

Outro problema que influencia na emancipação das vitimas de violência domestica é a multiculturalidade, que perpassa gerações legitimada, como, por exemplo, rituais, religiões e crenças, uma vez que, dificulta o discernimento da vítima pela imposição de dogmas, assim sendo, a vítima permanece vinculada ao agressor impedindo que consiga se desvencilhar do circulo da violência. Neste caso, os instrumentos garantidos pelo Estado para o exercício da condição de agente ficam restritos a mudança de paradigma, mas mostra-se indispensáveis para desencadear transformações em longo prazo que podem gerar avanços positivos no combate a violência.

\section{AMARTYA SEN E A CONDIÇÃO DE AGENTE DA MULHER}

\subsection{A CONDIÇÃo DE AGENTE ATIVo}

Preliminarmente é necessário determinar o significado do emprego do termo "agente" na teoria de Amartya Sen para poder compreender o contexto a que se refere à condição de agente, e que segundo o qual, o termo "agente" esta condicionado a identidade do individuo que por suas ações gera transformações sociais, motivado e julgado por seus próprios valores, mas que refletem na vida de outras pessoas. Portanto agente para Sen:

O agente às vezes é empregado na literatura sobre economia e teoria dos jogos em referencia a uma pessoa que está agindo em nome de outra (talvez sendo acionada por um "mandante"), cujas realizações devem ser avaliadas

${ }^{11}$ SEN, Amartya. Desenvolvimento como liberdade. 2010,p.247 
CAMARGO, Carolina; SPERANDIO, Marilin Soares. Mulher e a condição da sustentabilidade social: uma análise a partir de Amartya Sen. Revista Eletrônica Direito e Política, Programa de PósGraduação Stricto Sensu em Ciência Jurídica da UNIVALI, Itajaí, v.11, n.3, 30 quadrimestre de 2016. Disponível em: www.univali.br/direitoepolitica - ISSN 1980-7791

à luz dos objetivos da outra pessoa (o mandante). Estou usando o termo gente não nesse sentido, mas em sua acepção mais antiga - "mais grandiosa" - de alguém que age e ocasiona mudança social e cujas realizações podem ser julgadas de acordo com seus próprios valores e objetivos, independentemente de avaliarmos ou não também segundo algum critério externo. Este estudo ocupase particularmente do papel da condição de agente do individuo como membro do público e como participante de ações econômicas, sociais e políticas (interagindo no mercado e até mesmo envolvendo-se, direta ou indiretamente, em atividades individuais ou conjuntas na esfera política ou em outras esferas $)^{12}$.

Nesta senda, a Condição de Agente ativo para Sen é a liberdade e a responsabilidade do agir do individuo pertencente a sociedade motivada por condições instrumentais disponibilizadas pelo Estado.

Logo, as ações deste cidadão devem estar de acordo com as necessidades da realidade do meio em que está inserido, pois a sua tomada de decisão acarretará em mudanças na sua vida e de outras pessoas que o circundam, e assim, deixam de ser considerados pacientes para se tronarem agentes da mudança social.

[...] Com oportunidades sociais adequadas, os indivíduos podem efetivamente moldar seu próprio destino ajudar uns aos outros. Não precisam ser vistos sobretudo como beneficiários passivos de engenhosos programas de desenvolvimento. Existe de fato, uma sólida base racional para reconhecermos o papel positivo da condição de agente ativo livre e sustentável - e até mesmo o papel positivo da impaciência construtiva ${ }^{13}$.

A condição de agente ativo das mulheres é uma conquista alcançada pelo desenvolvimento da sociedade, que e razão da evolução, positivou direito e garantias a mulher legitimando-a como sujeito de direitos reconhecendo direito à propriedade, e oportunidades de educação, saúde e trabalho. Assim, o fortalecimento da proteção da mulher vítima de violência extrema, como num estupro coletivo, passou a gerar preocupação pela violação de direitos e

\footnotetext{
${ }^{12}$ SEN, Amartya. Desenvolvimento como liberdade. 2010, p. 34.

${ }^{13}$ SEN, Amartya. Desenvolvimento como liberdade. 2010, p. 26.
} 
CAMARGO, Carolina; SPERANDIO, Marilin Soares. Mulher e a condição da sustentabilidade social: uma análise a partir de Amartya Sen. Revista Eletrônica Direito e Política, Programa de PósGraduação Stricto Sensu em Ciência Jurídica da UNIVALI, Itajaí, v.11, n.3, 30 quadrimestre de 2016. Disponível em: www.univali.br/direitoepolitica - ISSN 1980-7791

garantias voltados a mulher. Sobre a importância da violência contra a mulher Sen analise este processo na Índia um país democrático que possuía altos índices e afirma:

É um progresso bastante positivo que a violência contra as mulheres tenha por fim se tornado uma questão política importante na Índia, com a indignação pública que se seguiu a um terrível estupro coletivo cometido em dezembro de 2012. O debate em torno desse tema tem chamado a atenção para inúmeros aspectos da discriminação de gênero (incluindo, mas não apenas, a insensível atitude da polícia em relação a denúncias de violência sexual) que vinham sendo em grande parte negligenciados por muito tempo ${ }^{14}$.

Segundo Amartya Sem, a condição de agente ativo das mulheres representa a oportunidade de crescimento e a promoção da relação de pertença e do empoderamento na sociedade para que ocorra então a mudança social que surtirá efeitos na vida de mulheres, homens e crianças em decorrência da mulher deixar de ser somente receptora passiva de ações que visem melhorar seu bemestar, passando a promover sua própria vida:

Já não mais receptoras passivas de auxílio para melhorar seu bem-estar, as mulheres são vistas cada vez mais, tanto pelos homens como para elas próprias, como agentes ativo de mudanças: promotoras dinâmicas de transformações sociais que podem alterar a vida das mulheres e dos homens ${ }^{15}$.

Desta forma, é indispensável o comprometimento do Estado para gerar instrumentos que auxiliem a mulher na transformação da sua condição de receptora passiva em agente ativo. Nesta senda, para que ocorra a identidade da mulher para o exercício da condição de agente ativo e sua emancipação é necessário que o Estado oportunize, por exemplo, saúde, educação, renda e trabalho.

\footnotetext{
${ }^{14}$ SEN, Amartya. Glória Incerta: a Índia e suas contradições. Tradução de Ricardo Doninelli Mendes e Leila Coutinho. São Paulo. Companhia das Letras, 2015. p.6

${ }^{15}$ SEN, Amartya. Desenvolvimento como liberdade. 2010, p.246.
} 
CAMARGO, Carolina; SPERANDIO, Marilin Soares. Mulher e a condição da sustentabilidade social: uma análise a partir de Amartya Sen. Revista Eletrônica Direito e Política, Programa de PósGraduação Stricto Sensu em Ciência Jurídica da UNIVALI, Itajaí, v.11, n.3, 30 quadrimestre de 2016. Disponível em: www.univali.br/direitoepolitica - ISSN 1980-7791

Ademais a teoria da Condição de Agente Ativo de Amartya Sen engloba ambos os gêneros, responsabilizando tanto homens como mulheres por suas ações e não ações. Para Zambam a Condição de Agente dependendo da situação que está sendo analisada apresenta diferentes necessidades:

A condição de agente é um conceito amplo, que influência os variados aspectos da vida de uma pessoa e nas relações que decorrem do contexto onde está inserida. Por isso, em situações peculiares, a busca do bem-estar e a própria compreensão da condição de agente adquirem diferentes prioridades ${ }^{16}$.

A luta por liberdade e direitos iguais faz da mulher um agente ativo na sociedade, a partir do momento que assume sua própria vida, trabalhando, estudando e gerenciando a vida dos filhos, podendo optar dessa forma por sair de uma situação de violência por ter meios para a sua independência do agressor, já que por muitos anos a submissão era sua única opção.

O zelo com os filhos e o cuidado da casa, historicamente eram tarefas atribuídas somente às mulheres, na atualidade a mulher continua com estas atribuições, porém, o homem pela igualdade de gênero perdeu a imposição patriarcal da ideia de que casa é serviço de mulher e passou a desenvolver também estas tarefas, em razão de que ambos trabalham, estudam devendo a mulher não arcar com o duplo fardo na jornada diária.

As taxas de fecundidade diminuíram significativamente diante da condição ativa das mulheres, que através do empoderamento decide qual é o momento viável para a reprodução. Sendo assim, motivadas pelos efeitos na vida pessoal da mulher que diretamente é privada por uma gestação, a mulher pode optar por sua carreira e reconhecimento profissional antes da maternidade, e ainda tem o condão de evitar que estas mulheres sejam privadas da sua liberdade. Segundo Sem:

[...] o papel da condição de agente das mulheres também é particularmente importante para a redução das taxas de

\footnotetext{
16 ZAMBAM, Neuro José. Amartya Sen: Liberdade Justiça e desenvolvimento Sustentável. 2012. P.68.
} 
CAMARGO, Carolina; SPERANDIO, Marilin Soares. Mulher e a condição da sustentabilidade social: uma análise a partir de Amartya Sen. Revista Eletrônica Direito e Política, Programa de PósGraduação Stricto Sensu em Ciência Jurídica da UNIVALI, Itajaí, v.11, n.3, 30 quadrimestre de 2016. Disponível em: www.univali.br/direitoepolitica - ISSN 1980-7791

fecundidade. Os efeitos adversos da taxa de natalidade elevadas incluem a negação das liberdades substanciais devido a gestações frequentes e ao incessante trabalho de criar filhos - impostas rotineiramente a muitas mulheres $[\ldots]^{17}$.

A própria natureza da vida familiar - compartilhar um lar e viver conjuntamente - requer que os elementos de conflito não sejam efetivados de uma forma explícita (frisar constantemente os conflitos será considerado um sinal de união "fracassada"), e às vezes a mulher que sofre privação nem sequer é capaz de avaliar claramente o seu grau de privação relativa. De maneira análoga, a percepção de quem está fazendo que quantidade de trabalho "produtivo" ou de quem está "contribuindo" em que quantidade para a prosperidade da família pode ser grande influência, muito embora a "teoria" subjacente ao modo como as "contribuições" e a "produtividade" devem ser avaliadas possa ser raramente discutidas de maneira explicita ${ }^{18}$.

A assertiva acima é uma das grandes conquistas da mulher, que sai da escuridão sendo a sombra do marido passando a ser a luz da família, deixando de ser vista como um fracasso, mesmo que ainda existam privações no seio familiar, assim as mulheres deixam de serem consideradas como não produtivas, sendo inseridas na sociedade pelo reconhecimento da sua importância para o desenvolvimento de uma nação.

No que tange a Condição de Agente do indivíduo (homem ou mulher), esta representa a responsabilização das escolhas feitas, e os reflexos gerados. A identificação da pessoa com a Condição de agente ativa traz benefícios inerentes ao exercício dos direitos garantidos pelas leis e normas para o realizador da ação e a sociedade em conjunto.

Para Zambam, a tecnologia representa o caminho para o desenvolvimento, para condições melhores para a vida humana, inobstante o resultado alcançado vem se demonstrando diverso do pretendido, por práticas individualistas ou

\footnotetext{
${ }^{17}$ SEN, Amartya. Desenvolvimento como liberdade. 2010, p. 257

${ }^{18}$ SEN, Amartya. Desenvolvimento como liberdade. 2010, p.250.
} 
CAMARGO, Carolina; SPERANDIO, Marilin Soares. Mulher e a condição da sustentabilidade social: uma análise a partir de Amartya Sen. Revista Eletrônica Direito e Política, Programa de PósGraduação Stricto Sensu em Ciência Jurídica da UNIVALI, Itajaí, v.11, n.3, 30 quadrimestre de 2016. Disponível em: www.univali.br/direitoepolitica - ISSN 1980-7791

corporativas. Revelando o abuso da extração de recursos materiais visando o lucro e desestabilizando o equilíbrio ambiental e como consequência a inviabilidade da continuidade da biosfera e aduz:

Os recursos tecnológicos são um componente indispensável para as políticas do desenvolvimento não apenas por ampliarem a capacidade para a apropriação e a transformação dos bens disponíveis, mas, especialmente, por permitirem melhores condições para a vida humana e a organização interna e externa das sociedades, entre outras. Entretanto, a ação do homem por meio do uso da tecnologia tem se revelado bastante contraditória, porque muitas vezes é motivada por interesses individuais ou corporativos. Assim, de forma indiscriminada, ele se apossa dos recursos ambientais e aprimora as formas de domínio, comprometendo o agir individual, o conjunto das relações sociais, a convivência entre os povos, a condição de vida futuras gerações, a própria possibilidade da continuação da vida humana e o equilíbrio ambiental ${ }^{19}$.

Sen na obra Glória Incerta estabelece uma conexão do crescimento de uma nação ligado ao reconhecimento do desenvolvimento e empoderamento das mulheres, que não apenas se desenvolvem no seio familiar, mas que a partir do momento que obtém a sua liberdade e seu espaço começam a modificar também as condições sociais de seu país, baseados nessa certeza há uma analise no poder das mulheres e como elas podem contribuir para a redução das desigualdades e o desenvolvimento da Índia:

Dadas a disseminação e as formas da desigualdade de gênero na Índia, há uma necessidade urgente de se concentrar não só no que pode ser feito pelas mulheres indianas (por mais importante que isso seja), mas também no que as mulheres indianas podem fazer pela Índia ajudando a criar um país bem diferente ${ }^{20}$.

A importância da mulher na construção da identidade do indivíduo e da educação para o desenvolvimento das pessoas é indiscutível para Sen, que compara uma pessoa analfabeta há outra que cumpre pena. O conhecimento propicia a quem

19 ZAMBAM, Neuro José. Amartya Sen: Liberdade Justiça e desenvolvimento Sustentável. 2012, p.127-128.

20 SEN, Amartya. Desenvolvimento como liberdade. 2010, p.12 
CAMARGO, Carolina; SPERANDIO, Marilin Soares. Mulher e a condição da sustentabilidade social: uma análise a partir de Amartya Sen. Revista Eletrônica Direito e Política, Programa de PósGraduação Stricto Sensu em Ciência Jurídica da UNIVALI, Itajaí, v.11, n.3, 30 quadrimestre de 2016. Disponível em: www.univali.br/direitoepolitica - ISSN 1980-7791

está no cárcere o encontro com a sua liberdade e assim descreve elementos que traduzem a importância de uma educação básica:

O papel da educação básica no processo de desenvolvimento e progresso social é amplo e importantíssimo. Em primeiro lugar, a capacidade de ler, escrever e contar tem efeitos poderosos sobre a nossa qualidade de vida: a liberdade para compreender o mundo, para levarmos uma existência bem informada, para nos comunicarmos com os outros e, de um modo geral, para estarmos em contato com a realidade. $\mathrm{Na}$ sociedade contemporânea, em que tanta coisa depende da palavra escrita, ser analfabeto é como estar preso, e a educação escolar abre uma porta através da qual as pessoas podem escapar do encarceramento ${ }^{21}$.

Segundo refere Sen às oportunidades econômicas e emprego que dependem das nossas habilidades alcançadas pela educação. A escolarização do sujeito elementos necessários ao aprimoramento da sua profissão. Cada vez mais é exigido que o grau de instrução médio seja o ensino superior, visando que a pessoa tenha a ofertar um conhecimento prévio:

[...] as nossas oportunidades econômicas e perspectivas de emprego dependem bastante do nosso nível educacional e das nossas habilidades aprendidas. A capacidade de compreender a informação escrita e dominar as operações numéricas envolvidas em tarefas específicas pode ser uma qualificação imprescindível até mesmo para tarefas simples, sobretudo com o aumento da especialização nos processos de produção e distribuição. A necessidade de educação expandiu-se em especial no mundo do comércio globalizado, e o sucesso de economias como a China tem se baseado de forma substancial na capacidade de uma força de trabalho razoavelmente escolarizada para atender às demandas de controle de qualidade e treinamento de habilidades envolvidas na produção de bens e serviços para o mundo como um todo 22 .

Sendo assim, outro elemento é a insegurança que a falta de educação escolar causa na população, demonstrando que uma pessoa analfabeta tem menos

${ }^{21}$ SEN, Amartya. Glória Incerta: a Índia e suas contradições. Tradução de Ricardo Doninelli Mendes e Leila Coutinho. São Paulo. Companhia das Letras, 2015. p.175

22 SEN, Amartya. Glória Incerta: a Índia e suas contradições. Tradução de Ricardo Doninelli Mendes e Leila Coutinho. São Paulo. Companhia das Letras, 2015. p.175 
CAMARGO, Carolina; SPERANDIO, Marilin Soares. Mulher e a condição da sustentabilidade social: uma análise a partir de Amartya Sen. Revista Eletrônica Direito e Política, Programa de PósGraduação Stricto Sensu em Ciência Jurídica da UNIVALI, Itajaí, v.11, n.3, 30 quadrimestre de 2016. Disponível em: www.univali.br/direitoepolitica - ISSN 1980-7791

condições de acompanhar as escolhas de seus governantes, a importância da educação, trabalho que tornam mais difícil o exercício da condição de agente ativo:

[...] o analfabetismo abafa a voz política da população e, portanto, contribui diretamente para sua insegurança. A conexão entre a voz e a segurança das pessoas é muitas vezes subestimada. Isso não significa negar que as democracias possam ser eficazes mesmo na presença de tantos analfabetos; esse ponto com certeza precisa ser enfatizado, pois está perdido no fundo do argumento reacionário, com frequência aventado, de que uma população analfabeta não tem nenhuma serventia para os direitos democráticos ${ }^{23}$.

Para Sen a importância da educação no crescimento e expansão das liberdades é fundamental para o exercício da democracia, das capacidades e da condição de agente ativo na sociedade e o comprometimento com a educação pode ser observado em uma grande democracia como a Índia que mesmo tendo fortes influencias culturas, pela divisão por castas e outros fatores, incentiva sua população para que tenha acesso a educação:

Diferentemente do que diz uma história anedótica bastante conhecida, segundo a qual os pais indianos muitas vezes não querem - ou até proíbem - que seus filhos sejam escolarizados, em especial as meninas, é impressionante ver a facilidade com que a importância da educação para todos é percebida até mesmo pelas famílias mais pobres e desfavorecidas da Índia. Essa foi uma das principais conclusões do Relatório público sobre educação básica (conhecido como Relatório Probe, da sigla em inglês), publicado em 1999, e também de trabalhos mais recentes, por exemplo, o do Pratichi Trust. $5 \mathrm{E}$, ao contrário do que se afirma com frequência, os estudos empíricos sistemáticos não encontraram nenhuma resistência séria por parte dos pais a mandar seus filhos - meninas ou meninos - às escolas, desde que sejam acessíveis, eficazes e seguras.

Nos casos em que existe certa relutância, a tendência é que se deva à estrutura de escolarização, por exemplo, em virtude da preocupação com a segurança das crianças,

23 SEN, Amartya. Glória Incerta: a Índia e suas contradições. Tradução de Ricardo Doninelli Mendes e Leila Coutinho. São Paulo. Companhia das Letras, 2015. p.175 
CAMARGO, Carolina; SPERANDIO, Marilin Soares. Mulher e a condição da sustentabilidade social: uma análise a partir de Amartya Sen. Revista Eletrônica Direito e Política, Programa de PósGraduação Stricto Sensu em Ciência Jurídica da UNIVALI, Itajaí, v.11, n.3, 30 quadrimestre de 2016. Disponível em: www.univali.br/direitoepolitica - ISSN 1980-7791

sobretudo de meninas, quando as escolas estão localizadas a uma considerável distância de onde os pais trabalham, ou quando a escola tem apenas um professor, que pode não estar presente todos os dias ${ }^{24}$.

Nesta senda, segundo Amartya Sem, um dos temas que merece destaque pela relevância na mudança social é o empoderamento das mulheres, pelo fomento e desenvolvimento que causam nos Países que contam com governantes mulheres como é o caso do Brasil que há pouco menos de um ano era governado por uma mulher. Conforme já afirmado mulheres empoderadas reduzem taxas de mortalidade e fecundidade, passando a contribuir para que a sociedade e sua comunidade local prosperem.

A leitura, o conhecimento e a multidisciplinariedade fazem com que individuo desenvolva as suas capacidades e possa escolher o trabalho, os relacionamentos e as oportunidades que lhe é ofertada. Para Sen a educação é fundamental para o exercício da democracia, mas a falta dela não afasta a democracia apenas torna seu acesso mais restrito.

Por fim a teoria de Sen significa o rumo escolhido por meio das nossas decisões, e a Condição de Agente representa a consciência da responsabilidade das nossas escolhas, e liberdades, já que segundo o autor somos os direcionadores do sentido das nossas vidas, então se a preocupação com a violência incorporar nos resultados que devamos produzir as condutas individuais e coletivas poderão ser modificadas reduzindo as taxas de homicídio.

A violência doméstica alcança proporções maiores do que o sofrimento somente da mulher vítima, surge desse contexto as vítimas ocultas ou silenciosas que são também vítimas os filhos do casal que presenciam os fatos e por diversas vezes sofrem calados a dor, a tristeza e a impossibilidade de não poder fazer nada para sair dessa realidade violenta.

As consequências desses traumas não podem ser mensuradas, são testemunhos carregados na memória, e que por diversas vezes podem desencadear a

${ }^{24}$ SEN, Amartya. Glória Incerta: a Índia e suas contradições. Tradução de Ricardo Doninelli Mendes e Leila Coutinho. São Paulo. Companhia das Letras, 2015. p.179 
CAMARGO, Carolina; SPERANDIO, Marilin Soares. Mulher e a condição da sustentabilidade social: uma análise a partir de Amartya Sen. Revista Eletrônica Direito e Política, Programa de PósGraduação Stricto Sensu em Ciência Jurídica da UNIVALI, Itajaí, v.11, n.3, 30 quadrimestre de 2016. Disponível em: www.univali.br/direitoepolitica - ISSN 1980-7791

reprodução da violência na vida adulta e na própria constituição de novas famílias.

Poderíamos pensar que nos dias atuais com a globalização e a celeridade das informações em um mundo considerado e imaginado como igualitário seria impossível à vítima não buscar ajuda, já que há tantos meios de divulgação e órgãos como delegacias especializadas para a proteção da mulher, mas a dificuldade de rompimento do vínculo com o agressor pela dependência é um fator que prejudica a vítima na ruptura do laço afetivo.

Porém a realidade das mulheres vítimas de violência doméstica compreende um campo complexo em que o medo pelas incertezas futuras representa a sua realidade, onde a falta de emprego, e oportunidades encarcera as mulheres por não possuírem condições de trabalhar e sustentar seus filhos sem o agressor.

Outro ponto a ser discutido são os crimes passionais que assolam as mulheres, crimes violentos e cruéis que muitas vezes são premeditados, que ocorrem movidos por uma violenta emoção, de um exemplo clássico como o de Nelson Hungria que "O homem encontra sua mulher na cama e a mata movido pela violenta emoção de encontrar sua amada nos braços de outro homem para lavar a sua honra". Há outros elementos que fundamentam e completam o crime passional além da violenta emoção como a somatória de sentimentos e fatores biológicos e genéticos de pré-disposição a condutas violentas.

Segundo dados da ONU/BRASIL meninas negras tem $50 \%$ mais risco que as brancas de serem mães entre os 15 e 17 anos e meninas negras de 15 e 17 anos tem mais chance de não trabalhar nem estudar comparado as demais crianças adolescentes brasileiras; $21 \%$ das meninas de 14 a 16 anos estão ocupadas são trabalhadoras domesticas sem carteira assinada e $15 \%$ das brasileiras que passam por um aborto legalizado tem menos de 15 anos.

A liberdade de uma pessoa é indispensável para a organização de uma sociedade justa, sendo a sua privação uma não condição de agente que segundo Zambam afeta o equilíbrio do ordenamento social: 
CAMARGO, Carolina; SPERANDIO, Marilin Soares. Mulher e a condição da sustentabilidade social: uma análise a partir de Amartya Sen. Revista Eletrônica Direito e Política, Programa de PósGraduação Stricto Sensu em Ciência Jurídica da UNIVALI, Itajaí, v.11, n.3, 30 quadrimestre de 2016. Disponível em: www.univali.br/direitoepolitica - ISSN 1980-7791

A atuação livre de uma pessoa é uma dimensão indispensável para a garantia de uma organização justa e equilibrada da sociedade, e isso inclui, especialmente os direitos políticos e a livre expressão. Nas situações nas quais as pessoas são privadas dessas prerrogativas, juntamente com a falta do bem-estar, ocorre o que se pode chamar de "condição de não agente", que afeta o equilíbrio do ordenamento social, priva a possibilidade de escolha das pessoas e confunde a compreensão e o processo de desenvolvimento ${ }^{25}$.

Dessa forma, a mulher vítima de violência doméstica é a negação da condição de agente. Pois sequer consegue perceber, que há mecanismos que possam ajudar na sua emancipação. O Estado deve estar comprometido ao combate da violência familiar, pois estas mulheres estão a mercê da vontade de seus companheiros que utilizam da força física e moral para promover tortura com o intuito de humilhar e submeter as mulheres a satisfazer suas necessidades sexuais, morais, materiais e intrínsecas a seus costumes.

\section{CONSIDERAÇÕES FINAIS}

Conclui-se que a sustentabilidade social da mulher requer mecanismos capazes de primeiramente garantir a sua segurança e erradicar as desigualdades sociais e posteriormente propiciar que a mulher se emancipe da condição de não agente.

A Condição de Agente ativa das mulheres na filosofia de Amartya Sen mostra a realidade enfrentada na sociedade atual, que busca a igualdade entre homens e mulheres e a dignidade. A mulher quando agente ativa passa a ser a gerenciadora da sua vida e de seu seio familiar, é a oportunidade de empoderamento que transforma e da força para que consiga desempenhar um papel na sociedade.

No que tange a democracia, cumpre destacar que esta é fundamental para o desenvolvimento das capacidades do indivíduo. Partindo de um contrato social seletivo onde mulheres e minorias foram excluídas, se percebe a historicidade da

25 ZAMBAM, Neuro José. Amartya Sen: Liberdade Justiça e desenvolvimento Sustentável. Passo Fundo: IMED, 2012. p.72 
CAMARGO, Carolina; SPERANDIO, Marilin Soares. Mulher e a condição da sustentabilidade social: uma análise a partir de Amartya Sen. Revista Eletrônica Direito e Política, Programa de PósGraduação Stricto Sensu em Ciência Jurídica da UNIVALI, Itajaí, v.11, n.3, 30 quadrimestre de 2016. Disponível em: www.univali.br/direitoepolitica - ISSN 1980-7791

exclusão da mulher como sujeito de direitos. Mas a democracia garante que as leis e politicas publicas possam ser mecanismos potentes no combate a violência de gênero. A quebra do paradigma da violência domestica é necessária, porém, seu caminho demonstra-se lento, em decorrência da cultura arraigada.

Por fim, os instrumentos necessários a para o exercício da condição de agente em Sen, são fundamentais para a sustentabilidade social da mulher, ainda que dependa diretamente de um país sob regime democrático.

\section{REFERÊNCIAS DAS FONTES CITADAS}

Mapa da Violência 2015. Homicídio de mulheres no Brasil. Disponível: www.mapadaviolencia.org.br Acesso em 10 de setembro de 2016.

NUSSBAUM, Martha C. The Frontiers of justice: disability, nationality, species membership. Cambridge: Harvard University Press, 2005

RAWLS, John. Direito dos Povos. Tradução de Luis Carlos Borges. São Paulo: Martins Fontes, 2001

SEN, Amartya. A Ideia de justiça. São Paulo: Companhia das Letras, 2011.

Letras, 2010.

Desenvolvimento como liberdade. São Paulo: Companhia das

- Glória Incerta. a Índia e suas contradições. Tradução de Ricardo Doninelli Mendes e Leila Coutinho. São Paulo. Companhia das Letras, 2015.

ZAMBAM, Neuro José. Amartya Sen: Liberdade Justiça e desenvolvimento Sustentável. Passo Fundo: IMED, 2012.

Submetido em: outubro/2016

Aprovado em: novembro/2016 